EXTENDED REPORT

\title{
The evaluation of a humidifying device for vitreoretinal surgery
}

\author{
B J T Vote, M K Russell, A Newland, P J Polkinghorne
}

Br J Ophthalmol 2004;88:1582-1584. doi: 10.1136/bjo.2004.045591

See end of article for authors' affiliations ....................

Correspondence to: Mr Philip Polkinghorne, Auckland Eye Department, Auckland Hospital, Private bag 92019, Auckland, New Zealand; philip@ pipolk.co.nz

Accepted for publication 2 June 2004
Aim: To study the feasibility of humidifying air during vitreoretinal surgery and measure the water content of air before and after intraocular transit.

Methods: The absolute water content of air was measured in a series of six eyes undergoing fluid-air exchange during macular hole surgery. Infrared absorption spectroscopy was used to determine the water content of the air infusing and exiting each eye. After baseline measurements for each eye were recorded, a second fluid-air exchange was performed and the effect of humidifying the air infusion was documented.The humidifying device used in this study was a prototype adapted from a commercially available respiratory humidifier and enables humidified air to be delivered at a controlled temperature. Results: The water content of air increased following intraocular transit, implying dehydration occurs from the intraocular surfaces. For a standard airline infusion the mean increase in water content of air egressing from an eye was $13.4 \mathrm{mg} / \mathrm{l}$. Humidifying the air reduced the rate of water loss by nearly $90 \%$.

Conclusions: Significant water losses can occur from eyes undergoing fluid-air exchange. Humidifying the infused air can substantially reduce the dehydrating effect during an air exchange. This outcome may have a beneficial effect in reducing cataract formation and visual field defects associated with macular hole surgery.
$\mathrm{F}$ luid-air exchange during vitreoretinal surgery is used frequently as a tool for retinal re-attachment. The surface tension of air in an aqueous environment is such that subretinal fluid can be hydraulically removed as air is pumped into the eye. While this manoeuvre is usually simple and effective, complications of fluid-air exchange are well known and may lead to cataract and retinal injury. ${ }^{12}$ One of the mechanisms that may be important in causing damage arises as a consequence of dehydration of the intraocular surfaces. ${ }^{3}$ We have previously reported on the parameters governing water vapour in air and report herein the results of humidifying air in vitreoretinal surgery. ${ }^{4}$

\section{METHODS}

\section{Study aims}

We sought to quantify the loss of water content occurring from six eyes undergoing macular hole surgery during fluid gas exchange using ambient air. We consequently sought to demonstrate the ability of a prototype humidifier for vitreoretinal surgery to produce highly humidified air for infusion and to determine if humidification of infusion air reduces water loss from the eye during fluid-air exchange. In one patient the infusion line became blocked during the change to humidified air. This single data set was excluded from analysis.

The dehydration effects of the partially humidified air on the intraocular interfaces can be determined from Dalton's law of evaporation which states: the rate of evaporation is related to the vapour pressure deficit at the fluid-air interface and a "wind function." 56 The latter function describes the flow velocity and wind pattern over the water source while the former term defines the difference in partial pressure of water vapour in air when saturated (which is temperature dependent) and that of the delivered gas; in this case, air.

Dalton's law of evaporation can be expressed in the following form:

$E=f(u)^{*}\left(e_{s}-e_{a}\right)$

Where $f(u)$ is called the "wind function"

and $\mathrm{e}_{\mathrm{s}}=$ saturation vapour pressure

$\mathrm{e}_{\mathrm{a}}=$ vapour pressure in the air.

In order to calculate an absolute value for the rate of evaporation, it is necessary to derive a wind function describing the complex fluid flow dynamics within the eye. This value is not yet determined. However, it can be shown mathematically that Dalton's law can also be used to define the differential change in the rate of evaporation between ambient room air and humidified air, without requiring the wind function. Accordingly the percentage change in the rate of evaporation for the six eyes under the two conditions described was calculated. ${ }^{56}$

\section{Equipment used}

Absolute water content (absolute humidity, mg/l) was measured using an infrared hygrometer, which provides for real time readings (Fisher and Paykel Healthcare, Auckland, New Zealand). This device determines the water content of air by measuring the absorption spectra in the infrared portion of the electromagnetic spectrum and comparing with a known standard. The accuracy of the hygrometer is plus or minus $1 \mathrm{mg} / \mathrm{l}$. The importance of measuring absolute as opposed to relative humidity of an air sample means the effect of temperature and ambient pressure can be ignored and has been previously discussed. ${ }^{4}$

The highly humidified air used during the fluid-air exchange was achieved using the Fisher \& Paykel MR820 humidifier. This is a prototype device adapted from a commercially available respiratory humidifier and enables humidified air to be delivered at a controlled temperature. Sterilisation of this unit was achieved by gamma irradiation and meets both the ISO 11137 and the BS/EN 552 standards (respectively, International Organisation for Standardisation and National Standard Body of the United Kingdom)

\section{Technique}

Measurements were made in a series of six eyes undergoing fluid-air exchange during macular hole surgery. After baseline measurements were recorded for each eye with ambient 
air, the eye was then refilled with balanced salt solution (Alcon, Fort Worth, TX, USA) and a second fluid-air exchange was performed.

The air infusion pressure was maintained at $26 \mathrm{~mm} \mathrm{Hg}$ for the duration of the surgery. The water content was measured 5 minutes after the completion of the initial air exchange and again some 5 minutes after the infused air was humidified. The infrared hygrometer was used to determine absolute humidity of the following:

- Ambient air

- Air exiting from the six eyes during standard fluid-air exchange performed with ambient air

- Air delivered to five eyes via the MR820 humidifier

- Air exiting from five eyes during fluid-air exchange conducted using humidified air

Ethics approval and informed consent was obtained from all patients.

Additional studies on the sites and extent of heat loss, together with measurements of water content of humidified air were conducted under controlled conditions in the laboratory.

\section{RESULTS}

The mean water content of the filtered air in the standard infusion line was $8.2 \mathrm{mg} / \mathrm{l}$ (range $8-10 \mathrm{mg} / \mathrm{l}$ ). Conversely the humidified air, heated to $37^{\circ} \mathrm{C}$ in the MR820 humidifier had a mean water content of $40.4 \mathrm{mg} / \mathrm{l}$ (range $40-40.6 \mathrm{mg} / \mathrm{l}$ ) as measured immediately after leaving the heating coil used to raise the ambient temperature of the infused air (just before connecting to three way tap and 20 gauge infusion line). However cooling and condensation of the water vapour occurred in the unheated portion of the humidified air line (that is, the 20 gauge infusion connecting between the three way tap and the eye). The heat losses were subsequently documented in the laboratory to be in the order of $10^{\circ} \mathrm{C}$, while the reduction in absolute water content along the unheated infusion line ranged from $10-20 \mathrm{mg} / \mathrm{l}$. Thus, though the humidifier was capable of delivering saturated air at body temperature, the technical issues of maintaining sterility meant the actual water content hovered around $25 \mathrm{mg} / \mathrm{l}$ which is equivalent to saturated air at $27^{\circ} \mathrm{C}$.

Under standard ambient conditions (that is, without the humidifying the airline) the mean water content egressing from the eyes was $20.84 \mathrm{mg} / \mathrm{l}$ (SD 1.182) while the mean water content of the air egressing from the eye with humidified air was $22.84 \mathrm{mg} / \mathrm{l}$ (SD 0.604). The difference in the mean water content under these two circumstances is statistically significant $(\mathrm{p}>0.001)$.

The introduction of the humidifier did not alter the flow rate of the air infusion as each unit was sealed and the tubing was of the same length and calibre as the ambient air line infusion.

The following partial pressures of water vapour $e_{a 1}$ (ambient conditions in the operating room), and $\mathrm{e}_{\mathrm{a} 2}$ (output from the humidifier) were obtained in this study. The partial pressure of water vapour at body temperature $\left(e_{s}\right)$ when the air is saturated is:

$\mathrm{e}_{\mathrm{s}}=6.280 \mathrm{kPa} \quad(47.10387 \mathrm{~mm} \mathrm{Hg}) \quad\left(37^{\circ} \mathrm{C}, 100 \%\right.$ relative humidity, $44 \mathrm{mg} / \mathrm{l}$ )

$\mathrm{e}_{\mathrm{al}}=1.145 \mathrm{kPa}(8.588 \mathrm{~mm} \mathrm{Hg})$

(mean ambient conditions in operating room: $20^{\circ} \mathrm{C}, 46 \%$ relative humidity, $8 \mathrm{mg} / \mathrm{l}$ )

(equivalent to $18 \%$ relative humidity at $37^{\circ} \mathrm{C}$ )

$\mathrm{e}_{\mathrm{a} 2}=5.725 \mathrm{kPa}(42.94103 \mathrm{~mm} \mathrm{Hg})$

(maximum output of humidifier: $40 \mathrm{mg} / \mathrm{l}, 35^{\circ} \mathrm{C}$ )

(equivalent to $91 \%$ relative humidity at $37^{\circ} \mathrm{C}$ )
Substituting the appropriate values (in $\mathrm{kPa}$ ) into Dalton's law, we obtain the following rates of evaporation:

The rate of evaporation $\mathrm{E}_{1}$ (when delivering ambient operating room air):

$E_{1}=f(u){ }^{*} 5.135$

The rate of evaporation $E_{2}$ (when delivering humidified air under ideal conditions):

$E_{2}=f(u)^{*} 0.555$

Under ideal circumstances, the active humidifier therefore shows a reduction of $89.2 \%$ in the rate of evaporation when compared to ambient operating room air.

\section{DISCUSSION}

The complications of fluid-air exchange in vitreoretinal surgery are poorly understood. Some adverse effects such as field defects are more commonly described in macular hole surgery yet similar intraocular manipulations occur during other retinal procedures. The reported frequency of field defect also varies considerably. ${ }^{78}$

Welch has maintained the main cause of postoperative field defects seen in patients undergoing macular hole surgery is the result of dehydration of the retina. ${ }^{3}$ Kokame and others have highlighted the importance of infusion pressure as a determinant of the intraocular pressure and reporting on the drying effects of high flow systems. ${ }^{9}$ Furthermore Hirata et al demonstrated field defects occur more frequently in eyes with higher infusion pressures and confirmed Welch's finding that field defects depended on the position of the infusion cannula. ${ }^{311}$ These authors concluded the field defect seen in their patients was likely to be caused by direct mechanical damage (by infusion pressure) to the inner retina. Similarly, Hasumura et al maintained direct mechanical trauma to the retina during air exchange was responsible for the adverse and localised effect on the retina seen in a series of experiments performed on rabbit eyes. ${ }^{2}$ More recently Hirata has demonstrated with a modified infusion cannula the pathological changes documented under similar experimental conditions could minimised with altered flow dynamics. ${ }^{12}$ We believe that altering infusion pressure and flow dynamics of infusion cannulae exerts a favourable effect on evaporation/dehydration by altering the wind function component of Dalton's law. Consequently, we believe that dehydration therefore is the ultimate mechanism by which visual field defect occurs, but that dehydration can be influenced by either infusion pressure/flow dynamics or by humidifying the infused air.

There is conflicting evidence on the merits of humidifying air in vitreoretinal surgery. Ohji et $a l^{13}$ found field defects could be eliminated by humidifying air but Hirata et al did not. ${ }^{11}$ Both these groups used a water bath to humidify the infused air. We have previously demonstrated that none of these experiments have effectively determined the underlying cause of the visual field defects as they have not distinguished between the interrelated factors that might determine dehydration fluxes within the eye. ${ }^{4}$ Furthermore, our previous study indicated that cold evaporation is a relatively ineffective method of humidifying air and the flaws inherent in using relative humidity in interpreting water content. We have demonstrated that the prototype MR820 humidifier used in our experiments can effectively humidify air to saturated body temperature levels. However, we have also documented in our experimental set up there are still heat losses as the humidified air passes from the humidifier to the eye through the unheated 20 gauge infusion line. This problem may be overcome by extending the heat coil to within millimetres from the eye, a technical issue which we are currently addressing. We believe this remains an important question and may help to provide an answer to the observed adverse effects on the eye. 
A novel approach to the issue of determining the optimal level of heat and humidity in respiratory medicine was to consider the energy balance under certain experimental conditions. ${ }^{6}$ These authors measured the temperature and humidity of inspired and expired air in intubated patients under variable conditions and found inspired air at body temperature and saturated was thermodynamically neutral. Air infusions for vitrectomy are an analogous situation and it is logical that infusing saturated body temperature air would also be thermodynamically neutral. Whether or not it is necessary to strive for this ideal in vitreoretinal surgery remains to be seen, as the threshold at which dehydration damage occurs is likely to be much lower than this. The concept of having a thermodynamic neutral value helps explain why the water content of the air egressing from the eyes is higher when the air is humidified.

This study does not yet conclusively answer the question of causation in visual field defects or the role of dehydration. However it does confirm that dehydration of the intraocular surfaces does occur and is not insignificant. Furthermore we have demonstrated that effective humidification of infused airlines can be obtained (that is, saturated at body temperature) with our prototype humidifier.

\section{CONCLUSION}

A significant increase in water vapour loss occurs during fluid-air exchange if the infused air is not humidified. This may result in dehydration injury to the intraocular surfaces and contribute to psychophysical abnormalities seen following vitreoretinal surgery. The MR820 humidifier is able to deliver highly humidified air to an eye and would theoretically eliminate dehydration injury to the retina during fluidair exchange. These findings allow further studies that can evaluate the importance of humidity and infusion pressure as independent risk factors during vitreoretinal surgery. Such an independent analysis will better determine the roles of dehydration and mechanical (infusion pressure) forces in visual fields defects during macular hole surgery.

\section{Authors' affiliations}

B J T Vote, M K Russell, P J Polkinghorne, Department of

Ophthalmology, Auckland, New Zealand

A Newland, Fisher and Paykel HealthCare Division, Auckland, New Zealand

Disclaimer: A Newland is a paid employee of Fisher and Paykel. Comment: Paper presented at Vitreous Society San Francisco and BEAVRS (British and Eire Association of Vitreoretinal Surgeons) Edinburgh, 2002.

\section{REFERENCES}

1 Thompson J, Glaser B, Sjaarda R, et al. Progression of nuclear sclerosis and long-term visual results of vitrectomy with transforming growth factor beta-2 for macular holes. Am J Ophthalmol 1995;119:48-54.

2 Hasumura T, Yonemura N, Hirata A, et al. Retinal damage by air infusion during vitrectomy in rabbit eyes. Invest Ophthalmol Vis Sci 2000;41:4300-4.

3 Welch J. Dehydration injury as a possible cause of visual field defect after pars plana vitrectomy for macular hole. Am J Ophthalmol 1997; 124:698-9

4 Vote B, Newland A, Polkinghorne P. Humidity devices in vitreoretinal surgery. Retina 2002;22:616-21.

5 Dalton J. On the absorption of gases by water and other liquids. Mem Liter Phil Soc Manchester, 1805;1:271-87.

6 Ryan S, Rankin N, Meyer E, et al. Energy balance in the intubated human airway is an indicator of optimal gas conditioning. Crit Care Med 2002:30:355-61.

7 Pendergast S, McCuen B, 2nd. Visual field loss after macular hole surgery. Ophthalmology 1996;103:1069-77.

8 Ezra E, Arden GB, Riordan-Eva P, et al. Visual field loss following vitrectomy for stage 2 and 3 macular holes. Br J Ophthalmol 1996;80:519-25.

9 Kokame G. Visual field defects after vitrectomy with fluid-air exchange. Br J Ophthalmol 2001;85:121.

10 Ishigooka H, Mawatari Y, Ogawa K. Prophylactic trials for prevention of visual field defect after vitrectomy for macular hole. Invest Ophthalmol Vis Sci 2000;41:1799-B45.

11 Hirata A, Yonemura N, Hasumura T, et al. Effect of infusion air pressure on visual field defects after macular hole surgery. Am J Ophthalmol 2000;130:611-16.

12 Hirata A, Yonemura N, Hasumura T, et al. New infusion cannula for prevention of retinal damage by infusion air during vitrectomy. Retina 2003;23:682-5.

13 Ohii M, Nao I, Saito Y, et al. Prevention of visual field defect after macular hole surgery by passing air used for fluid-air exchange through water. Am J Ophthalmol 1999;127:62-6. 